\title{
Clinical efficacy of conjoint fascial sheath suspension and frontalis muscle suspension in treating moderate or severe congenital ptosis and the effects on ocular surface and refractive status
}

\author{
$\mathrm{XUEHONG} \mathrm{PAN}^{1}$, TING WEI ${ }^{2}, \mathrm{XIAODONG} \mathrm{WANG}^{1}$ and $\mathrm{CHAO} \mathrm{XU}^{3}$ \\ ${ }^{1}$ Department of Medical Aesthetics, Yidu Central Hospital; ${ }^{2}$ Department of Acupuncture and Moxibustion, \\ Qingzhou Traditional Chinese Medicine Hospital, Qingzhou, Shandong 262500; ${ }^{3}$ Department of Burn \\ and Plastic Surgery, Zibo Central Hospital, Zibo, Shandong 255036, P.R. China
}

Received November 1, 2019; Accepted June 25, 2020

DOI: $10.3892 /$ etm.2020.9053

\begin{abstract}
Clinical efficacy of conjoint fascial sheath suspension and frontalis muscle suspension was explored in treating moderate or severe congenital ptosis and their effects on ocular surface and refractive status. A total of 75 patients with moderate or severe ptosis (108 eyes) treated in Yidu Central hospital from June 2014 to June 2019 were enrolled in this study, and divided into group A and group B. Group A was treated with conjoint fascial sheath suspension $(n=38,55$ eyes), while group B was treated with frontalis muscle suspension $(n=37$, 53 eyes). The following data of the two groups were compared: General baseline data, total correction efficiency, satisfaction, and ocular surface after surgery, refractive status, and complications at three months after surgery. The two groups showed no significant difference in general data $(\mathrm{P}>0.05)$, but group $\mathrm{A}$ showed higher total correction efficiency and satisfaction, and less complications than those in group $\mathrm{B}$ (all $\mathrm{P}<0.05)$. In addition, the two groups had no difference in terms of ocular surface, tear break-up time, or Schirmer test level after surgery (all $\mathrm{P}>0.05$ ), and showed no refraction changes after surgery $(\mathrm{P}>0.05)$. In terms of refractive status and ocular surface, the two surgery methods are not very different, but in terms of efficacy, conjoint fascial sheath suspension is more advantageous than frontalis muscle suspension, and it brings less complications, and enjoys a higher satisfaction, so it is worthy of promotion.
\end{abstract}

\section{Introduction}

Ptosis refers to the improper position of the upper eyelid edge relative to the upper corneoscleral rim not due to reasons

Correspondence to: Dr Chao Xu, Department of Burn and Plastic Surgery, Zibo Central Hospital, 54 Gongqingtuan Xi Road, Zhangdian, Zibo, Shandong 255036, P.R. China

E-mail: x6h22y@163.com

Key words: conjoint fascial sheath suspension, frontalis muscle suspension, ptosis, refractive status such as poor eyesight and blepharoptosis. Such a situation in a child at birth or in the first year after birth can be diagnosed as congenital ptosis, and unilateral ptosis accounts for $64.7-75.0 \%$ of all types of ptosis (1-3). Congenital ptosis can be classified into mild, moderate, or severe ptosis (4), which is mainly caused by the following reasons: The upper eyelid cannot lift or is in partial or complete ptosis due to hypoplasia of levator muscle, defects of Müller smooth muscle, or nerve defects of upper eyelid muscle $(5,6)$. Ptosis usually causes partial or complete pupillary block, and thus results in visual disturbance. If not corrected in time, it may lead to deprived amblyopia, seriously degrading visual function $(7,8)$.

There are many clinical treatment methods for moderate or severe congenital ptosis, and one of the most classic methods is frontalis muscle suspension (9). It connects the upper eyelid bone to the frontal muscle using suspension materials to help patients to open the eyelid with frontal muscle, so as to treat ptosis (10). However, this technology is prone to bring a high postoperative complication rate and recurrence rate (11). Therefore, conjoint fascial sheath suspension, a new clinical therapy, has gained favor from patients (12). This study focused on comparing the conjoint fascial sheath suspension and frontalis muscle suspension based on comparison of clinical efficacy, ocular surface, and refractive status to find out which one is more advantageous in the treatment of moderate or severe congenital ptosis.

\section{Patients and methods}

General materials. A total of 75 patients with moderate or severe congenital ptosis (108 eyes) treated in Yidu Cental Hospital (Qingzhou, China) from June 2014 to June 2019 were enrolled in this study, and divided into group A and group B. Group A was treated with conjoint fascial sheath suspension ( $n=38,55$ eyes), while group B was treated with frontalis muscle suspension ( $n=37,53$ eyes). group A consisted of 18 males (25 eyes) and 20 females (30 eyes) aged 18-34 years, with an average age of $21.5 \pm 3.3$ years. There were 17 patients ( 23 eyes) with moderate ptosis and 21 patients (32 eyes) with severe ptosis in group A. Group B consisted of 16 males (24 eyes) and 21 females (29 eyes) aged 19-35 years, with an average age of 
$22.3 \pm 2.7$ years. There were 17 patients ( 22 eyes) with moderate ptosis and 20 patients (31 eyes) with severe ptosis in group B.

The inclusion criteria were as follows: Patients diagnosed with moderate or severe congenital ptosis, patients with positive bell syndrome before surgery, patients who had not received any eyelid surgery, and patients with all required clinical data. The study was approved by the Ethics Committee of Yidu Central Hospital. All subjects and their family members were informed of the research purpose, and each subject provided a written informed consent.

Exclusion criteria were as follows: Patients with the neurosis of Marcus Gunn Jaw Winking syndrome, patients with connective tissue diseases or immunological diseases, patients with contraindications for eyelid surgery; patients with severe dysfunction in heart, lung, liver or kidney or hematopoietic failure, or patients with psychosis or family history of psychosis.

Methods. Each patient in group A was treated using the conjoint fascial sheath suspension as follows: i) The subcutaneous tissue was cut off along a designed cutting line. ii) Each patient was disinfected and draped, and then anesthetized through subcutaneous infiltration from conjunctival epithelium and upper eyelid. iii) The upper eyelid skin and subcutaneous tissue were cut open along the designed incision to cut off the loose skin.iv) The ocular anterior muscle of tarsus was cut off, and the tarsus edge was fully exposed. v) The orbital septum was lifted, and excess fat was removed. It was separated from the levator muscle. The exposed diaphragm was separated from levator muscle, and the conjunctivas were injected with $2 \%$ lidocaine, and separated from Miller muscle with water. The upper eyelid pal muscle was separated from Miller muscle aponeurosis at the site $5 \mathrm{~mm}$ above the hole, and the white conjoint fascial sheath (CFS) thickened tissue was exposed. vi) The CFS was pulled down, sutured with 6-0 nylon thread, and fixed at the middle, inner, and outer upper edge of the tarsus (1/3, respectively), so that the upper eyelid edge was $3 \mathrm{~mm}$ above the pupil when the eye was opened to look straight ahead, and both sides were basically symmetrical. vii) The incision at the upper edge of tarsus and the side of the eyelid edge was subject to subcutaneous mattress suture with 6-0 nylon to form double eyelid for adhesion. The incision was sutured at the middle, inner and outer of the eyelid (1/3, respectively). viii) From Miller muscle, the upper eyelid muscle and muscle complex were sutured to the bone margin, and then the skin incision due to the double eyelid surgery was sutured. ix) The eyelid was applied with erythromycin ointment, and bound up under pressure.

Each patient in group B was treated with frontalis muscle suspension: i) For unilateral ptosis, the incision of the affected double eyelid was designed according to half of the width in the healthy double eyelid to cut off loose skin. The auxiliary incision was designed in the lower $1 / 3$ under the affected eyebrow, with a length of $1.5 \mathrm{~cm}$, and the frontal muscle flap was designed to cover $\sim 1.5 \times 3.5 \mathrm{~cm}$. ii) Each patient was disinfected and draped conventionally, and then locally anesthetized through infiltration. iii) The upper eyelid skin and subcutaneous upper eyelid were cut open along the incision line to cut off the loose skin, and the orbicularis oculi muscle was cut open along the double eyelid line parallel to the upper edge of tarsus with a needle-shaped electric knife to explore the anterior tarsal fascia. iv) The auxiliary incision under the eyebrow at the affected side was cut open to the subcutaneous site, and the range of frontal muscle flap was designed before separation surgery at subcutaneous and periosteal levels. The incision and forehead muscle flap were cut off vertically to form tongue muscle flap, and its bleeding was stopped with electrocoagulation. v) A tunnel was formed with ophthalmic scissors by cutting it under the muscle toward the incision below eyebrow subcutaneously, and the frontal muscle flap was pulled down through the tunnel and sutured and fixed to the middle and upper edge of the anterior tarsal fascia, so that the eye could be basically symmetrical with that of the healthy side when opening to look straight ahead. vi) The upper edge of anterior tarsal fascia and muscle at the eyelid margin incision were sutured with 6-0 nylon thread to form double eyelid. The skin was sutured interruptedly with 7-0 nylon thread. Film was inserted into the incision under eyebrow for drainage, and subcutaneous skin and skin were sutured interruptedly with 6-0 nylon thread. vii) The eyelid was applied with erythromycin ointment, and bound up under pressure.

Observation indexes. i) The general baseline data of the two groups were compared. ii) The total correction efficiency of the two groups was also compared. Evaluation criteria (13): After surgery, the width of palpebral fissure, upper corneal mass, and cornea exposure of the patients were evaluated. If the upper eyelid edge of one patient was located at the site $1 \mathrm{~mm}$ from the corneal limbus, and the patient showed natural upper eyelid arc and symmetrical eyelids, the result was well corrected. If the eyelid edge of one patient was located between the site $1 \mathrm{~mm}$ above the corneal limbus or the site $2 \mathrm{~mm}$ below it, and the patient showed natural double-fold eyelid arc and acceptable upper eyelid correction, the result was fairly well corrected. The patient's upper eyelid edge should be located at the site $2 \mathrm{~mm}$ from the cornea when looking straight ahead. If the site of upper eyelid edge was $1-2 \mathrm{~mm}$ from the right site, the patient was undercorrected, while if it was more than $2 \mathrm{~mm}$ from the right site, the patient was overcorrected. The total correction efficiency $=$ (the number of well corrected patients + the number of fairly well corrected patients)/the total number of patients $\times 100 \%$. iii) The satisfaction of the two groups was compared: The patients were investigated at three months after surgery. Satisfaction $=$ (the number of patients satisfied with the surgery + the number of patients basically satisfied with the surgery)/the total number of patients $\mathrm{x} 100 \%$. iv) The ocular surface of the two groups was compared: The tear break-up time (BUT), Schirmer test (SIt) levels and corneal staining score (FL) of the patients were detected before surgery and at one week after surgery. The BUT of the patients was determined continuously three times. If the BUT was less than $10 \mathrm{sec}$, the tear film was judged as unstable. If the SIt observation time was $5 \mathrm{~min}$ and the wet length of the filter paper was longer than $5 \mathrm{~mm}$, the secretion could be determined to be low secretion. The corneal coloring in four quadrants need to be observed, with 3 points for dense point or patchy coloration, 2 points for slightly dense coloration, 1 point for scattered point coloration, and 0 points for no coloring, and a total of 12 points. v) The refractive status of the two groups was 
Table I. General baseline data of group A and group B [n(\%)](mean \pm SD).

\begin{tabular}{|c|c|c|c|c|}
\hline Group & $\begin{array}{c}\text { Group A } \\
(n=38 ; \text { no. of eyes, 55) }\end{array}$ & $\begin{array}{c}\text { Group B } \\
(\mathrm{n}=37 ; \text { no. of eyes, 53) }\end{array}$ & $t / \chi^{2}$ value & P-value \\
\hline Sex & & & 0.129 & 0.720 \\
\hline Male & $18(47.37)$ & $16(43.24)$ & & \\
\hline Female & $20(52.63)$ & $21(56.76)$ & & \\
\hline Age (years) & $21.5 \pm 3.3$ & $22.3 \pm 2.7$ & 1.147 & 0.255 \\
\hline Upper eyelid state (eye) & & & 0.141 & 0.708 \\
\hline Moderate & $25(45.45)$ & $26(49.06)$ & & \\
\hline Severe & $30(54.55)$ & $27(50.94)$ & & \\
\hline Ptosis (mm) & $2.753 \pm 0.834$ & $2.596 \pm 0.710$ & 1.052 & 0.295 \\
\hline Diabetes history & & & 0.123 & 0.725 \\
\hline Yes & $19(50.00)$ & $17(45.95)$ & & \\
\hline No & $19(50.00)$ & $20(54.05)$ & & \\
\hline Smoking & & & 0.014 & 0.907 \\
\hline Yes & $19(50.00)$ & $19(51.35)$ & & \\
\hline No & $19(50.00)$ & $18(48.64)$ & & \\
\hline Fond of drinking & & & 0.324 & 0.569 \\
\hline Yes & $16(43.24)$ & $18(48.64)$ & & \\
\hline No & $22(56.76)$ & $19(51.35)$ & & \\
\hline Obesity & & & 0.329 & 0.573 \\
\hline Yes & $21(47.62)$ & $18(50.00)$ & & \\
\hline No & $17(52.38)$ & $19(38.10)$ & & \\
\hline History of hypertension & & & 1.072 & 0.300 \\
\hline Yes & $16(43.24)$ & $20(54.05)$ & & \\
\hline No & $22(56.76)$ & $17(45.95)$ & & \\
\hline
\end{tabular}

compared: The refraction of the two groups was determined at 1 month after surgery. vi) The postoperative complications of the two groups were compared at three months after surgery: The complications such as upper eyelid entropion, exposure keratitis, conjunctival prolapse, and blepharal hematoma of the patients were analyzed at three months after surgery to count the complication rate.

Statistical analysis. The data were analyzed comprehensively and statistically using SPSS 19.0 (Asia Analytics Formerly SPSS). The enumeration data were analyzed using $\chi^{2}$, and measurement data were expressed as the (mean $\pm \mathrm{SD})$. The inter-group comparison in expression level before and after treatment was carried out using the paired t-test, and the comparison between group A and group B in expression level at the same time-point was carried out using the independent-samples t-test. $\mathrm{P}<0.05$ indicates a significant difference.

\section{Results}

Comparison between the two groups in general baseline data. It was necessary to compare the basic situation of group A and group B, such as age, sex, hypertension, diabetes, and individual preferences including smoking and drinking (all $\mathrm{P}>0.05$ ). Details are shown in Table I.
Comparison between the two groups in ocular surface at one week after surgery

i) The BUT level of the two groups was compared. The BUT level of group A before surgery and at one week after surgery was $16.03 \pm 3.96$ and $15.38 \pm 3.91 \mathrm{sec}$, respectively, and that of group B before surgery and at one week after surgery was $16.05 \pm 4.01$ and $15.57 \pm 3.78 \mathrm{sec}$, respectively. Therefore, both groups showed no significant BUT level change after surgery, and group A was also not much different from group B in BUT level before and after surgery (all $\mathrm{P}>0.05$ ). More details are shown in Fig. 1.

ii) The SIt level of the two groups was compared. The wet length of the filter paper of group A before surgery and at one week after surgery was $11.63 \pm 1.59$ and $11.18 \pm 1.41 \mathrm{~mm}$, respectively, and that of group B before surgery and at one week after surgery was $11.65 \pm 1.51$ and $11.37 \pm 1.38 \mathrm{~mm}$, respectively. Therefore, both groups showed no significant SIt level change after surgery, and group A was also not much different from group B in SIt level before and after surgery (all $\mathrm{P}>0.05$ ). More details are shown in Fig. 2.

iii) Comparison of FL levels after one week of operation between the two groups. Before surgery and one week after surgery, the FL levels of group A were $0.67 \pm 0.12$ and $2.82 \pm 0.34 \mathrm{~mm}$; the FL levels of group B were $0.68 \pm 0.11$ and $2.79 \pm 0.35 \mathrm{~mm}$. There were significant differences in FL levels in the two groups between before and after surgery $(\mathrm{P}<0.05)$. 
Table II. Refraction of group A and group B.

\begin{tabular}{|c|c|c|c|c|}
\hline Group & Group A $(n=38)$ & Group B $(n=37)$ & t value & P-value \\
\hline One day after surgery & $-4.72 \pm 1.03$ & $-4.87 \pm 1.12$ & 0.604 & 0.548 \\
\hline One month after surgery & $-4.02 \pm 1.04$ & $-4.33 \pm 1.02$ & 1.308 & 0.197 \\
\hline t value & 2.948 & 3.407 & & \\
\hline P-value & 0.004 & 0.001 & & \\
\hline
\end{tabular}

Table III. Comparison between group A and group B in the total correction efficiency.

\begin{tabular}{lcccc}
\hline Group & Group A (n=38) & Group B (n=37) & $\chi^{2}$ value & P-value \\
\hline Well corrected & $19(50.00)$ & $12(32.43)$ & - & - \\
Fairly well corrected & $14(36.84)$ & $11(29.73)$ & - & - \\
Undercorrected & $5(13.16)$ & $7(18.92)$ & - & - \\
Overcorrected & $0(0.00)$ & $7(18.92)$ & - & - \\
The total correction efficiency $(\%)$ & $33(86.84)$ & $23(63.16)$ & 4.756 & 0.029 \\
\hline
\end{tabular}

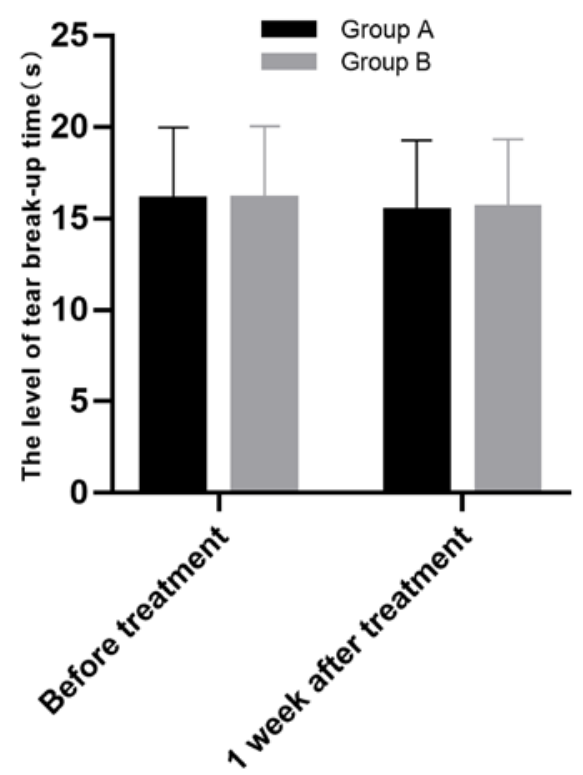

Figure 1. The tear break-up time of the two groups was compared before surgery and at one week after surgery. At one week after surgery, the tear break-up time of the patients was investigated, and continuously determined three times. If the tear break-up time was $<10 \mathrm{sec}$, the tear film was judged as unstable. There was no significant difference between the two groups in tear break-up time level before and after surgery $(\mathrm{P}>0.05)$, and neither group showed significant tear break-up level change after surgery $(\mathrm{P}>0.05)$.

The levels of FL in group A before and after surgery were not significantly different from those in group B ( $\mathrm{P}>0.05)$ (Fig. 3).

Refraction. The refraction of group A before surgery and at one week after surgery was $-4.72 \pm 1.03$ and $-4.02 \pm 1.04$, respectively, and that of group B before surgery and at one week after surgery was $-4.87 \pm 1.12$ and $-4.33 \pm 1.02$, respectively. Both groups showed significant refraction changes at one month after surgery $(\mathrm{P}<0.05)$, but group A was not significantly different from group $B$ in refraction before and after surgery $(\mathrm{P}>0.05)$. More details are shown in Table II.

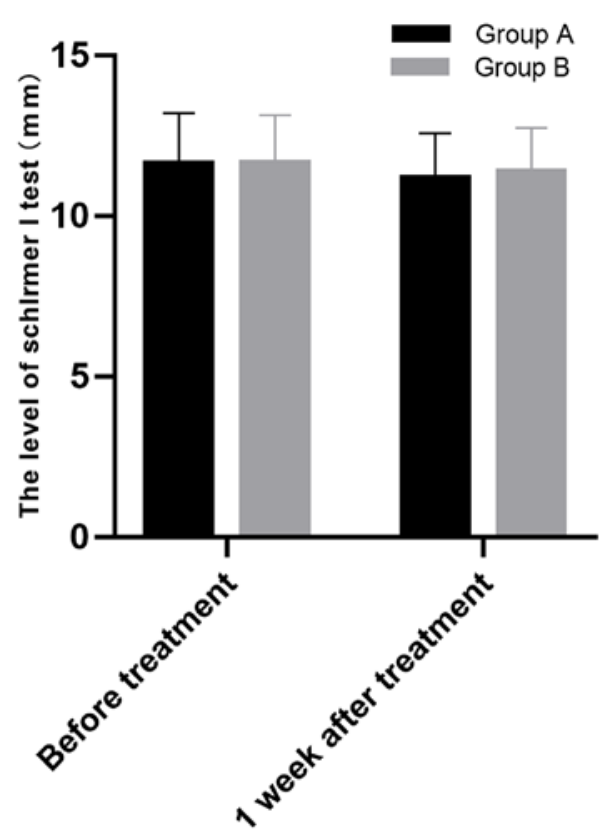

Figure 2. Comparison between the two groups in Schirmer test level. At one week after surgery, the Schirmer test level of the patients was determined. If the observation time was $5 \mathrm{~min}$ and the wet length of the filter paper was longer than $5 \mathrm{~mm}$, the secretion was judged as low. There was no significant difference between the two groups in Schirmer test level before and after surgery $(\mathrm{P}>0.05)$, and both groups did not show significant Schirmer test level change after surgery $(\mathrm{P}>0.05)$, and they showed high Schirmer test level.

Comparison between group A and group B in the total correction efficiency. Group A showed a total correction efficiency of $86.84 \%$, with 19 patients well corrected, 14 patients fairly well corrected, 5 patients undercorrected, and no patient overcorrected, and group B showed a total correction efficiency of $63.16 \%$, with 12 patients well corrected, 11 patients fairly well corrected, 7 patients undercorrected, and 7 patients overcorrected, so the total correction efficiency of group A was significantly higher than that of group $\mathrm{B}(\mathrm{P}<0.05)$. Details are shown in Table III. 
Table IV. Comparison of satisfaction between the two groups [n(\%)].

\begin{tabular}{lcccc}
\hline Group & Group A (n=38) & Group B (n=37) & $\chi^{2}$ value & P-value \\
\hline Satisfied & $21(55.26)$ & $16(43.24)$ & - & - \\
Basically satisfied & $15(39.48)$ & $11(29.73)$ & - & - \\
Dissatisfied & $2(5.26)$ & $10(27.03)$ & - & - \\
Satisfaction (\%) & $36(94.74)$ & $27(72.97)$ & 6.607 & 0.010 \\
\hline
\end{tabular}

Table V. Comparison between group A and group B in postoperative complications at three months after surgery [n(\%)].

\begin{tabular}{lcccc}
\hline Group & Group A (55 eyes) & Group B (53 eyes) & $\chi^{2}$ value & P-value \\
\hline Upper eyelid entropion & $0(0.00)$ & $3(5.66)$ & - & - \\
Exposure keratitis & $1(1.82)$ & $5(9.43)$ & - & - \\
Conjunctival prolapse & $1(1.82)$ & $5(9.43)$ & - & - \\
Blepharal hematoma & $2(3.63)$ & $1(1.81)$ & - & - \\
Complication rate & $4(7.27)$ & $14(26.43)$ & 7.121 & 0.008 \\
\hline
\end{tabular}

Comparison between the two groups in satisfaction. Group A showed a satisfaction of $94.74 \%$, with 21 patients satisfied with the surgery, 15 patients basically satisfied, and 2 patients dissatisfied with it, and group B showed a satisfaction of $72.97 \%$, with 16 patients satisfied with the surgery, 11 patients basically satisfied, and 10 patients dissatisfied, so the satisfaction of group A was significantly higher than that of group B $(\mathrm{P}<0.05)$. Details are shown in Table IV.

Comparison between the two groups in postoperative complications at three months after surgery. Group A showed a complication rate of $7.27 \%$, with no upper eyelid entropion, 1 patient suffering from exposure keratitis, 1 patient suffering from conjunctival prolapse, and 2 patients suffering from blepharal hematoma, and group B showed a complication rate of $26.43 \%$, with 3 patients suffering from upper eyelid entropion, 5 patients suffering from exposure keratitis, 5 patients suffering from conjunctival prolapse, and 1 patient suffering from blepharal hematoma, so the complication rate of group A was significantly lower than that of group B after surgery $(\mathrm{P}<0.05)$. More details are shown in Table V.

\section{Discussion}

Upper eyelid ptosis is a relatively common eye disease requiring correction surgery (14). Common correction methods include the frontalis muscle suspension and the emerging conjoint fascial sheath suspension $(15,16)$. The purpose of this study was to compare the efficiency of the two methods in treating moderate and severe congenital ptosis.

First we compared the efficacy of conjoint fascial sheath suspension and that of frontalis muscle suspension based on comparison of them in the total correction efficiency, satisfaction, and complications. Results showed that group A had significantly higher total correction efficiency, less complications and higher satisfaction than group B. The joint fascia sheath is a relatively independent connective tissue structure

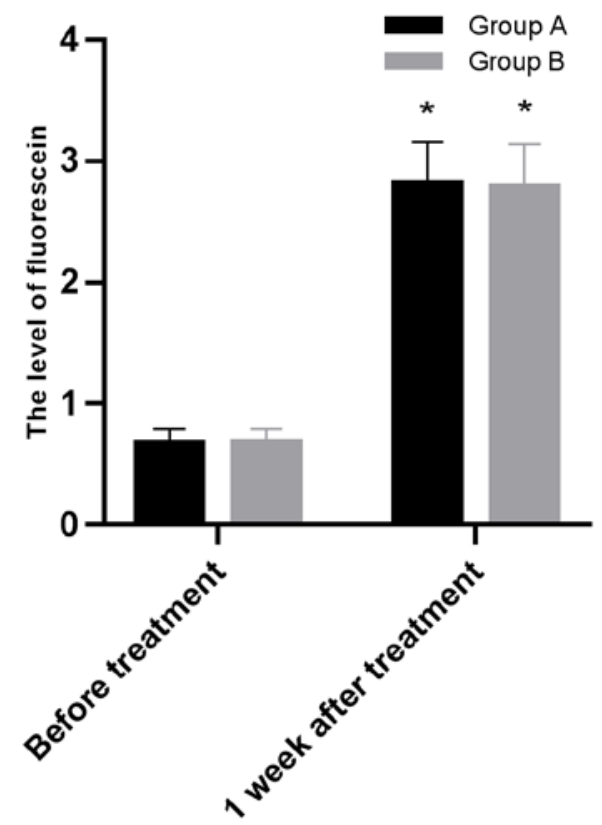

Figure 3. Comparison of corneal staining scores between the two groups. One week after surgery, the corneal staining scores of the patients were compared. There was a significant difference in corneal staining scores in the two groups between before and after surgery $(\mathrm{P}<0.05)$. There was no significant difference in corneal staining score between the two groups before and after surgery $(\mathrm{P}>0.05)$. ${ }^{*} \mathrm{P}<0.05$, compared with before surgery.

between the superior rectus and upper eyelid muscles, with a clear boundary. It is rich in elastic fibers and mainly contains oculomotor nerves. Therefore, in terms of physiology and anatomy, the structure of the combined fascia sheath is better than the frontal muscle flap. Because of the principles of physiology and anatomy, in theory, fascia sheath suspension could be combined with frontalis flap suspension $(17,18)$. Some studies have concluded that frontalis muscle suspension has obvious defects, because it usually causes insufficient correction, greatly impacts the appearance of eyelid, brings many 
postoperative complications and even leads to exposure keratitis (19-21), and some studies have found that conjoint fascial sheath suspension is much more advantageous than frontalis muscle suspension, with better efficacy and fewer complications $(22,23)$. Conjoint fascial sheath suspension contributes to more natural movement of eyelid edge in blinking, and it is more biomechanical and involves a smaller anatomical scope, so it can effectively avoid a series of complications, and is suitable for the treatment of patients under recurrence after frontalis muscle suspension (24). A study by Zhang et al found that compared with frontalis muscle suspension, conjoint fascial sheath suspension had advantages including contributing to beautiful and natural appearance, providing high safety, bringing high satisfaction rate, causing fewer complications, and providing strong physiology, which was worthy of clinical reference (25). Based on the above conclusions, we considered conjoint fascial sheath suspension was more effective than frontalis muscle suspension.

The two groups were compared in ocular surface at one week after surgery, finding that after surgery, corneal staining scores (FL) in group A and group B were significantly increased; the groups showed few BUT and SIt level changes, and there was no significant difference between them in the two aspects. A similar study also revealed that both conjoint fascial sheath suspension and frontalis muscle suspension caused only slightly different BUT and SIt levels (26). The above results indicate that BUT and SIt levels have scarce connection with the surgical method.

Compared with previous clinical studies on the treatment of combined fascial sheath suspension and frontal flap suspension, the greatest advantage of this experiment is that not only the efficiency and the incidence of complications, but also the diopters were compared with confirm the effect of two different treatments on the vision of the two groups of patients. Abnormal ptosis of the upper eyelid during primary gaze causes narrow palpebral fissure, and increases contact area between the eyelid and ocular surface, so upper eyelid ptosis greatly compromises the eyesight of the patients $(27,28)$. In this study, the refractive status of the two groups before and after surgery were compared with assess the role of surgery methods in improving eyesight. We found that both groups showed significant refraction changes at one month after surgery, but group A was not significantly different from group B in refraction before and after surgery. It suggested that both surgery methods could improve refraction, thus improving the eyesight. Based on the results of this experiment, although the differences in diopter, BUT, and SIt levels between the two groups of patients were not obvious, it is clear that the patients who used the combined fascial sheath suspension had better correction effects and fewer complications. The two treatments have obvious effects on reducing the refractive power after operation, but combined fascia sheath suspension has better correction effects and fewer complications, so the patient's satisfaction is higher.

This experiment still has some shortcomings. First, the number of samples is small, which affects the richness of the samples. Second, conjoint fascial sheath suspension is only compared with frontalis muscle suspension. In future, conjoint fascial sheath suspension should also be compared with other surgery methods besides frontalis muscle suspension, and the sample size should be more abundant to better demonstrate the advantages of conjoint fascial sheath suspension through comparison.

In conclusion, in terms of refractive status and ocular surface, the two surgery methods are not very different, but in terms of efficacy, conjoint fascial sheath suspension is more advantageous than frontalis muscle suspension, and it brings less complications, and enjoys a higher satisfaction, so it is worthy of promotion.

\section{Acknowledgements}

Not applicable.

\section{Funding}

No funding was received.

\section{Availability of data and materials}

The datasets used and/or analyzed during the present study are available from the corresponding author on reasonable request.

\section{Authors' contributions}

XP and CX conceived and designed the study. XP, TW, XW and $\mathrm{CX}$ were responsible for the acquisition, analysis and interpretation of the data. TW drafted the manuscript. XP revised the manuscript critically for important intellectual content. All authors read and approved the final manuscript.

\section{Ethics approval and consent to participate}

The study was approved by the Ethics Committee of Yidu Central Hospital (Qingzhou, China). Signed informed consents were obtained from the patients and/or guardians.

\section{Patient consent for publication}

Not applicable.

\section{Competing interests}

The authors declare that they have no competing interests.

\section{References}

1. Salman MS and Clark IH: Eyelid retraction in isolated unilateral congenital blepharoptosis. Front Neurol 8: 190, 2017.

2. Lee JH and Kim YD: Surgical treatment of unilateral severe simple congenital ptosis. Taiwan J Ophthalmol 8: 3-8, 2018.

3. Allard FD and Durairaj VD: Current techniques in surgical correction of congenital ptosis. Middle East Afr J Ophthalmol 17: 129-133, 2010.

4. Matayoshi S, Pereira IC and Rossato LA: Surgical treatment of congenital blepharoptosis. Rev Bras Oftalmol 73: 202-209, 2014.

5. Vyas KS, Kim U, North WD and Stewart D: Frontalis sling for the treatment of congenital ptosis. Eplasty 16: ic12, 2016.

6. Quaranta-Leoni FM, Sposato S, Leonardi A, Iacoviello L and Costanzo S: Timing of surgical correction for the treatment of unilateral congenital ptosis: Effects on cosmetic and functional results. Orbit 36: 382-387, 2017.

7. Zhou F, Ouyang M, Ma D, Liu G and Cheng H: Combined surgery for simultaneous treatment of congenital ptosis and coexisting strabismus. J Pediatr Ophthalmol Strabismus 54: 288-294, 2017. 
8. Paik JS, Kim SA, Park SH and Yang SW: Refractive error characteristics in patients with congenital blepharoptosis before and after ptosis repair surgery. BMC Ophthalmol 16: 177, 2016.

9. Mokashi AA, Stead RE and Abercrombie LC: Brow suspension using 3-0 Prolene. Eye (Lond) 25: 819, 2011.

10. Arajy ZY: Open loop fascial sling for severe congenital blepharoptosis. J Craniomaxillofac Surg 40: 129-133, 2012.

11. Farahat HG, Badawi NM, Mandour SS and Nage SA: Comparison of fasica lata and prolene suture in frontalis suspension surgery: Frontalis muscle suspension. Menoufia Med J 30: 502, 2017.

12. Ahn TJ, Kim JH, Lee EI, Lew DH, Kim NH, Park RH, Kim KT and Song SH: Nonincisional conjoint fascial sheath suspension: A novel technique for minimally invasive blepharoptosis correction. Ann Plast Surg 79: 334-340, 2017.

13. Pan E, Yu J, Zhang S, Nie Y and Li Q: Retrospective analysis of the effect of Hering's law on outcomes of surgical correction of ptosis. Ann Plast Surg 80: 242-244, 2018

14. Hwang K, Shin YH and Kim DJ: Conjoint fascial sheath of the levator and superior rectus attached to the conjunctival fornix J Craniofac Surg 19: 241-245, 2008.

15. Sokol JA, Thornton IL, Lee HB and Nunery WR: Modified frontalis suspension technique with review of large series. Ophthalmic Plast Reconstr Surg 27: 211-215, 2011.

16. Holmström H and Santanelli F: Suspension of the eyelid to the check ligament of the superior fornix for congenital blepharoptosis. Scand J Plast Reconstr Surg Hand Surg 36: 149-156, 2002.

17. Zuo L, Wang XX, Huang XY, Zhang JL and Du YY: A modified levator resection technique involving retention of the levator palpebrae superioris muscle suspension system for treatment of congenital ptosis. Aesthetic Plast Surg 41: 856-862, 2017.

18. Yadav C, Saini A and Maji PK: Energy efficient facile extraction process of cellulose nanofibres and their dimensional characterization using light scattering techniques. Carbohydr Polym 165: 276-284, 2017

19. Farooq SM and Wani EA: Frontalis sling surgery: Silicon rod versus autogenous fascia lata in congenital ptosis. Int J Med Sci Public Health 5: 6, 2016.
20. Lee YJ and Park DD: Frontalis transfer and closed silicone rod frontalis suspension. Aesthetic Plast Surg 22: 3-9, 2016.

21. Wilson ME and Johnson RW: Congenital ptosis. Long-term results of treatment using lyophilized fascia lata for frontalis suspensions. Ophthalmology 98: 1234-1237, 1991.

22. Lin W, Xu Y and Ye FL: Comparative study on conjoint fascial sheath suspension and levator muscle resection for moderate or severe congenital ptosis. Int Eye Sci 16: 1193-1195, 2016.

23. Zhao YN, Ge HG and Shen QL: Comparative study on conjoint fascial sheath suspension and the simple frontalis muscle suspension for moderate or severe ptosis. Int Eye Sci 17: 1790-1792, 2017.

24. Xin LI, Lu MT, Jiang Y, Zhou WK, Zheng YM, Wu HY and Zhang L: Clinical study on conjoint fascial sheath suspension in the treatment of moderate and severe ptosis. J Reg Anat Operative Surg 27: 333-336, 2018.

25. Zhang F, Sun Y and Liu L: Clinical efficacy of conjoint fascial sheath of the levator and superior rectus attached to conjunctival fornix suspension surgery in treatment of severe blepharoptosis. Chin J Med Aesthet Cosmetology 23: 399-401, 2017.

26. Zhang D, Guo B and Cai W: Effect of frontal muscle aponeurosis flap suspension surgery for severe congenital ptosis in children. Minerva Pediatr 71: 358-361, 2019.

27. Ma L, Mu X, Wang J and Liu H: Conjoint fascia sheath suspension for treatment of moderate to severe ptosis of the upper eyelid and observation of postoperative upper eyelid movement. Int J Clin Exp Med 11: 12531-12538, 2018.

28. Zhu T, Ye X, Xu P, Wang J, Zhang H, Ni H, Su Z and Ye J: Changes of corneal tomography in patients with congenital blepharoptosis. Sci Rep 7: 6580, 2017.

This work is licensed under a Creative Commons Attribution-NonCommercial-NoDerivatives 4.0 International (CC BY-NC-ND 4.0) License. 